\title{
The Frequency of Sexual Perpetration in College Men: A Systematic Review of Reported Prevalence Rates from 2000-2017
}

\author{
RaeAnn E. Anderson \\ University of North Dakota, raeann.anderson@UND.edu \\ Kristin E. Silver \\ Alyssa M. Ciampaglia \\ Amanda M. Vitale \\ Douglas L. Delahanty
}

\section{How does access to this work benefit you? Let us know!}

Follow this and additional works at: https://commons.und.edu/psych-fac

Part of the Psychology Commons

\section{Recommended Citation}

RaeAnn E. Anderson, Kristin E. Silver, Alyssa M. Ciampaglia, et al.. "The Frequency of Sexual Perpetration in College Men: A Systematic Review of Reported Prevalence Rates from 2000-2017" (2019). Psychology Faculty Publications. 11.

https://commons.und.edu/psych-fac/11

This Article is brought to you for free and open access by the Department of Psychology at UND Scholarly Commons. It has been accepted for inclusion in Psychology Faculty Publications by an authorized administrator of UND Scholarly Commons. For more information, please contact und.commons@library.und.edu. 
The Frequency of Sexual Perpetration in College Men: A Systematic Review of Reported Prevalence Rates from 2000-2017

RaeAnn E. Anderson ${ }^{1,2^{*}}$, Kristin E. Silver ${ }^{3,8}$, Alyssa M. Ciampagliaa ${ }^{4,5 \dagger}$, Amanda M. Vitale ${ }^{6,7 \dagger}$, \& Douglas L. Delahanty ${ }^{1}$

${ }^{1}$ Psychological Sciences, Kent State University, 144 Kent Hall, Kent, OH 44242

2 Psychology, University of North Dakota, 501 N. Columbia Road, 2000 Columbia Hall Grand Forks, ND 58202

${ }^{3}$ Psychology, University of Akron, 290 E. Buchtel Ave, Akron OH 44325

${ }^{4}$ Psychology, St. Joseph’s University, 5600 City Ave. Philadelphia, PA 19131

${ }^{5}$ Pulmonary Medicine, Children Hospital of Philadelphia, 3401 Civic Center Blvd., Philadelphia, PA 19104-4399

${ }^{6}$ Research and Development Program, Bronx Veteran's Administration, 130 West Kingsbridge Road, Bronx NY 10468

${ }^{7}$ Department of Neurosciences, Icahn School of Medicine, Mt. Sinai, 1425 Madison Ave, New York NY 10025

${ }^{8}$ National Institute of Justice, $8107^{\text {th }}$ Street, NW, Washington, DC 20531

†these authors contributed equally to the manuscript and are listed in alphabetical order *corresponding author: raeann.anderson@und.edu; 501 N. Columbia Road, Room 2000, Grand Forks, ND 58203

Acknowledgments: The authors wish to thank librarian Ms. Marilia Yesenia Antunez for her help in conducting the search of databases. 


\begin{abstract}
Background: The prevalence of sexual perpetration in college men is unknown. Prior reviews of sexual violence prevalence rates have produced wide-ranging estimates, likely due to wide variation in measurement strategies.

Objectives: This paper systematically reviewed research findings (from 2000-2017) regarding prevalence rates of sexual perpetration in college men and measurement strategies.

Data Sources: PsycINFO and Web of Science databases.

Eligibility Criteria: Empirical reports published between 2000-2017 that included male participants, available in English, and reported lifetime prevalence findings in Canadian or American college students.

Participants: Data from 78 independent samples including 25,524 college men.

Results: The average prevalence rate of any sexual perpetration was $29.3 \%(\mathrm{SD}=16.8)$, and the average rate of rape was 6.5\% (SD = 6.3). Studies that used non-Sexual Experiences Survey (SES) based questionnaires recorded higher prevalence rates (41.5\%) than SES-using studies (26.2\%). At least sixteen different sexual perpetration questionnaires were identified. Modifying standardized questionnaires was extremely common; this was reported in over half the studies. Studies using modified standardized questionnaires found higher prevalence rates of sexual perpetration than studies using non-modified standardized questionnaires.

Limitations: This report focused exclusively on college men in the United States and Canada. Conclusions and Implications: On average, 29\% of college males report engaging in behaviors defined as sexual perpetration; however, there was a strong influence of measurement strategy on reported rates.
\end{abstract}

Keywords: sexual perpetration; sexual aggression; sexual coercion; campus sexual assault; measurement; assessment; prevalence; rape 
The Frequency of Sexual Perpetration in College Men: A Systematic Review of Reported Prevalence Rates from 2000-2017

Sexual violence, defined as any sexual activity obtained without consent, is endemic on college campuses in the United States; approximately one in five U.S. college women will experience victimization (Breiding, Basile, Smith, Black, \& Mahendra, 2015; Muehlenhard, Peterson, Humphreys, \& Jozkowski, 2017). The negative health consequences of sexual violence victimization are varied and long-lasting (Koss, 1993), affecting almost every aspect of health and well-being. Although research on college sexual violence began in earnest in the 1970s, this topic has received increasing attention as of late, including recognition by President Obama (2014) concluding with one of the first national, presidential reports on sexual violence and the public awareness campaign “It’s On Us” (The White House Council on Women and Girls, 2014). The increase in public attention on sexual violence against women has continued more recently with the \#MeToo social media campaign, a feminist activism project focused on raising awareness of sexual harassment and violence (Mendes, Ringrose, \& Keller, 2018). Yet, corresponding attention focused on understanding and preventing sexual violence perpetration, defined as obtaining sexual activity from another person without their consent, has lagged. To prevent sexual violence, a range of interventions, including those that focus on sexual perpetration, are needed. However, a significant barrier in this field of study continues to be difficulty and inaccuracy in the measurement of sexual perpetration behavior (for example, see Bouffard \& Goodson, 2017). The goal of the present paper was to systematically review research findings regarding both the prevalence rates of sexual perpetration in college men as well as the extent to which different measurement strategies influenced reported prevalence rates. 


\section{Prevalence of Sexual Violence Perpetration}

In contrast to research on sexual victimization, there have been very few large-scale national or epidemiological studies on sexual perpetration. Indeed, there have been at least six large-scale, national, or epidemiological studies on the prevalence and consequences of sexual violence victimization in women, including: the Association of American Universities Campus Climate Survey (Cantor et al., 2015), Historically Black College and University Campus Sexual Assault Study (Krebs et al., 2011); Campus Sexual Assault Study (Krebs, Lindquist, Warner, Fisher, \& Martin, 2007); Drug-facilitated, Incapacitated, and Forcible Rape: A National Study (Kilpatrick, Resnick, Ruggiero, Conoscenti, \& McCauley, 2007), National College Women Sexual Victimization Study (Fisher, Cullen, \& Turner, 2000), and the Koss Scope of Rape study (Koss, Gidycz, \& Wisniewski, 1987). Further, there have also been important and relevant largescale studies focused on sexual violence victimization with non-college populations, including the annual National Crime Victimization Survey (The Bureau of Justice Statistics, n.d.), and the National Intimate Partner and Sexual Violence Survey NISVS (Black et al., 2011).

We could only identify one similarly large-scale study on sexual perpetration in college men: the Koss Scope of Rape Study (1987). There are some (albeit limited) more recent data on the prevalence of intimate partner violence perpetration from the National Epidemiological Survey on Alcohol and Related Conditions (Smith, Homish, Leonard, \& Cornelius, 2012), and youth dating violence perpetration from the Growing Up with Media Study (Ybarra, Espelage, Langhinrichsen-Rohling, Korchmaros, \& Boyd, 2016). However, the lack of large scale research on violence perpetration in young adults and college students, especially sexual violence perpetration, is striking. Koss et al.’s (1987) landmark study was the first to assess sexual victimization and perpetration in college students and introduced a revision of the first Sexual 
Experiences Survey (the 1987 SES vs. the 1982 SES) as the first behaviorally specific self-report measure of sexual victimization and sexual perpetration. This study found that $25.1 \%$ of nearly 3000 college men reported some type of sexual perpetration; the prevalence of rape was estimated at 4.4\%. The SES (and subsequent revisions) remain the standard tools for this field. Yet, the literature regarding sexual perpetration and the measurement of sexual perpetration has evolved considerably since 1987. For instance, in the 1987 study, to assess sexual perpetration, the nouns from the victimization items were merely changed to assess perpetration. As noted in the most recent major revision of the Sexual Experiences Survey (Koss et al., 2007), this approach conflates the victim's experience with the perpetrator's. Although the current unbalanced state of the literature may be influenced by measurement/methodological challenges (Abbey, 2005), these discrepant research efforts may inadvertently perpetuate a bias toward victim-blaming by ultimately de-emphasizing the behavior of the perpetrator.

Some researchers have attempted to address this imbalance in research foci; for instance, Krebs et al. (2007) examined sexual perpetration in a sample of 1375 college men as part of the Campus Sexual Assault Study. This study found a sexual violence perpetration prevalence rate of approximately 2.5\%. However, as they note in their report, "we have concerns about the validity of the perpetration data” (section 5, page 28). They argue that their findings likely underestimate the extent of sexual perpetration as a result of a combination of measurement limitations and intentional underreporting by male participants (Krebs et al., 2007). Their measurement strategy consisted of perpetration questions based on slight alterations to victimization questions and a two-stage approach in which positive answers to a more general question (i.e., screening questions) triggered follow-up items (see also Krebs et al., 2017). 
Research has suggested differing rates of endorsement for scales that followed a twoversus one-stage approach. For instance, Krahé and colleagues (2015), used a one-stage strategy (i.e., comprehensive items, presented all at once) to assess sexual violence perpetration and found prevalence rates ranging from 5.5\% to $48.7 \%$ in 3480 young adults aged $18-27$ in ten European countries. Notably, Krahé et al. conducted rigorous preliminary research to develop a standardized questionnaire that was used (in an appropriate translation) in every study country. This questionnaire included cues regarding sexual behavior (e.g., I put my penis in someone’s vagina) as well as sexual tactics (e.g., I used physical force: Krahé et al., 2016; Krahé \& Vanwesenbeeck, 2015). For more on one-stage vs. two-stage strategies see Krebs et al., 2017.

Also supporting the hypothesis that the findings of Krebs et al. (2007) could be an underestimate, Strang and Peterson (2017)’s work demonstrated that unintentional underreporting related to misinterpretation of items is as likely a source of error as intentional underreporting. In other words, respondents are equally likely to underreport because they do not understand an item as they are to underreport because they want to provide a socially desirable response. Thus, any review of sexual perpetration prevalence rates should also account for the validity of, and variation in, measurement strategies as they affect reported prevalence rates.

\section{Measurement Strategies for Assessing Sexual Violence Perpetration}

Despite the lack of epidemiological data on rates of campus sexual perpetration, there are a large number of smaller studies using college convenience samples. The most recent review of these studies suggested a prevalence rate of 5\% for rape perpetration and 25\% for any type of sexual perpetration; however, this review is nearly 20 years old (Spitzberg, 1999). These findings, and others, highlight a discrepancy between the much larger number of women who report experiencing rape (25\%) and the smaller number of men who report perpetration of rape 
(5\% - Kolivas \& Gross, 2007; Spitzberg, 1999). Multiple explanations have been offered to account for this inconsistency, including the possibility that a small number of men assault a large number of women, but current data do not support this hypothesis (Kolivas \& Gross, 2007; Swartout et al., 2015). Rather, a growing body of research suggests measurement inconsistencies as one systematic source of variation in prevalence ratings and in sexual violence findings more generally (Bouffard \& Goodson, 2017; Spitzberg, 1999; Tharp et al., 2013).

In the case of sexual violence perpetration, the explanation that proliferation in measurement strategies creates systematic variance in the literature may appear counter-intuitive as many, if not most, studies report using the original SES or the most recent revision, the Sexual Experiences Survey - Short Form Perpetration (SES-SFP). However, upon closer inspection, many of these studies report altering the SESs, which could result in changes in prevalence (as well as the psychometric properties of the SES).

As noted by Cook, Gidycz, Koss, and Murphy (2011), the measurement of sexual victimization must include the following three elements: behaviorally-specific descriptions of the sexual act (e.g., someone put their penis in my vagina), descriptions of the tactic used to obtain the act (e.g., took advantage of me while I was intoxicated), and non-consent. These elements reflect the components of definitions of sexual violence - a sexual act obtained via a specific tactic without consent. One common misconception we observe in sexual violence perpetration research is the presumption that the necessary elements for assessing perpetration are the same as those for assessing sexual violence victimization. In reality, research has only recently begun to identify the necessary elements for assessing sexual violence perpetration. A burgeoning literature demonstrates how even very small changes in wording can impact reported rates of sexual violence perpetration. Abbey, Parkhill, and Koss (2005) demonstrated that reported rates 
of sexual violence perpetration increased when the tactic was described before the sexual act. Further, Rueff and Gross (2017) demonstrated that altering the phrase designed to cue nonconsent "when she didn’t want to” in the 1982 and 1987 SESs to something more behaviorally specific "who at first resisted your advances, but due to your continued arguing and/or pressuring...stopped resisting,” increased prevalence rates from 14.9 to $26.6 \%$ for unwanted sexual contact and from 10.0 to $14.3 \%$ for coercion/rape. Thus, the minimal necessary elements to assess sexual perpetration are unclear in the literature, and even small changes in measurement strategy can affect prevalence rates.

\section{Current Study}

The purpose of the present paper was to systematically review the literature on the prevalence of sexual perpetration published since the last identified review (Spitzberg, 1999), with an additional focus on the extent to which differences in measurement strategies affected rates. We chose to focus on measurement strategies because measurement issues have been repeatedly cited in the literature as a serious methodological issue potentially hindering rigorous scholarship on sexual violence. Specifically, three major issues have been related to measurement variations: 1. variation in sexual victimization prevalence rates (Fedina, Holmes, \& Backes, 2018; Peterson, Voller, Polusny, \& Murdoch, 2010); 2. the strength of findings regarding risk factors for sexual violence perpetration (Tharp et al., 2013); and 3. explanation for discrepant and unusual findings on sexual perpetration (Krebs et al., 2007). Given findings on the sensitivity of even small changes in measurement strategy on prevalence rates (Abbey, Parkhill, \& Koss, 2005; Hamby \& Koss, 2003; Rueff \& Gross, 2017), we coded these variables in detail in order to highlight best practices in sexual perpetration measurement. Based on the above literature, the current study has the following aims: 
1. Examine the average and range of prevalence rates for multiple types of sexual perpetration in college men, including overall perpetration, verbal coercion perpetration, and rape perpetration.

2. Investigate the impact of measurement strategy on reported prevalence rates, including the effects associated with specific questionnaires and specific modifications/strategies within questionnaires.

\section{Methods}

We followed the 2009 PRISMA guidelines to develop the study protocol (Liberati et al., 2009) and followed these guidelines in the reporting of our methods.

\section{Inclusion and Exclusion Criteria}

Our inclusion criteria for the review were: empirical studies published after 1999

(including dissertations) that included men, studies written in English, and studies that reported lifetime prevalence findings on any type of sexual perpetration in Canadian or American college students. We focused on the US and Canada given the shared cultures and schooling systems of these countries. We constrained our search to college populations rather than community or incarcerated populations to capture a large enough swath of literature to make measurement comparisons while retaining some homogeneity in the sample. We excluded studies that reported exclusively on sexual harassment or sexual victimization, examined non-American or Canadian college students, recruited only women, reported prevalence rates for shorter time periods, or used procedures that made reported prevalence rates meaningless (e.g., recruited 30 participants with a history of perpetration and 30 participants without such history). We excluded studies of women’s sexual perpetration given methodological concerns that current tools for assessing perpetration lack construct validity with women; although perpetration in women is likely vastly 
underestimated (Buday \& Peterson, 2015). These criteria have the potential to reify gender stereotypes about sexual violence and we urge readers to use our results to build a better and more inclusive science of sexual violence.

\section{Search Strategy}

A systematic search of the literature was conducted in PsycINFO to identify studies that reported the prevalence of sexual perpetration in college men between January 2000 and December 2017. We used January 2000 as a delimiter as prior systematic reviews have included literature published prior to the year 2000 (e.g., Spitzberg, 1999). We used the following keywords: college/university/campus, and (rape/sexual coercion/sexual aggression/sexual perpetration), and men/males with the boolean operator NOT “military/veteran” OR “incarcera*”. This strategy resulted in 281 hits including peer-reviewed articles, dissertations, and book chapters. We repeated this search strategy in the Web of Science database to include articles from other literatures, such as criminology. This search produced 573 hits. Thus, our initial search generated a combined total of 854 citations to be screened; 101 of these citations appeared in both searches. A final list of 753 citations to be screened was created after excluding duplicates. In addition, a list of 41 frequently cited articles on sexual violence perpetration was generated from reading articles identified in the search above and from the first author's personal experience. Of these articles, only 8 were not already included on the citation list from the systematic search; ultimately only one of these articles met inclusion criteria. See Figure 1 for a PRISMA diagram of the search and screening process.

We completed the screening in two stages. Our initial screening procedure was designed to omit articles that did not meet inclusion criteria on the basis of reading the abstract. For example, citations that reported only on women or on students from another country were 
immediately excluded. Authors RA and KES completed the initial screening of the 754 citations generated in the search. Secondary screening of the remaining citations was completed by all coauthors (except DLD) as part of study coding. At this stage, the results section was reviewed as part of the coding process to ensure that the citation reported a lifetime prevalence rate for sexual perpetration among college men. When a coder identified a citation for likely exclusion during the secondary screening, another coder also screened the citation for exclusion. To code the reasons for exclusion, only one reason was recorded: the reason that was most obvious. Our final list of citations included 77 unique citations. A complete list of included and excluded citations can be found in Appendices 1 and 2.

\section{Coding Strategy}

Piloting. Authors REA and AMV completed initial piloting of coding procedures by reviewing and coding approximately 30 articles to extract prevalence and measurement data. After piloting, it was determined to focus on prevalence findings that covered a similar time period (rather than lifetime vs. past year vs. past three months) and to code in detail any changes made to the questionnaires used to assess sexual violence perpetration.

Final procedures. The first author and three graduate level trainees read and coded each of the 77 manuscripts. Each manuscript was coded twice, independently, by two different coders. After the first and second entries were completed, all entries were compared to identify discrepancies. Each coder was assigned a set of entries to review for discrepancies. Discrepancies that were not easily resolved were discussed to reach consensus.

Training. Coders received in-depth and ongoing training from the first author. Coders were trained using written materials, didactic lectures, and regular meetings. Training activities included coding example manuscripts together and discussing coding challenges during monthly 
conference calls. Coders were provided reference materials (examples of common measures, codebook with instructions, and coded examples). Coders completed quizzes on coding procedures and coded articles as a team quarterly during conference calls to prevent coder drift.

\section{Variables}

Two main types of variables were coded in addition to basic characteristics (study N, year, etc): reported prevalence of sexual perpetration and measurement strategy.

Prevalence data. For studies that reported sexual violence perpetration prevalence rates for both male and female participants, we coded only the men's data. We coded N's and calculated percentages from the Results section rather than relying exclusively on what authors reported in the Abstract or Participants sections. We coded overall prevalence for any type of sexual violence perpetration, combining all possible sub-types. We also coded prevalence rates for the specific sub-types of rape and verbal coercion. We chose to exclude unwanted sexual contact from sub-type coding as this type of sexual perpetration was less frequently reported, is defined quite variably (Basile, Smith, Breiding, Black, \& Mahendra, 2014; Fedina et al., 2018), can be difficult to distinguish from sexual harassment (see Quick \& McFayden, 2017 for review), and is less clearly tied to health consequences (Turchik \& Hassija, 2014). We used the Koss et al., (2007) definitions of perpetration types to guide our coding of perpetration sub-types given (1) they are widely used and reflected in current measurement practices, (2) they correspond to matching definitions of sexual victimization, and (3) they were reached by consensus among sexual violence scholars (Koss et al., 2007). Sexual coercion (referred to in this study as verbal coercion) is defined as any type of sexual intercourse obtained via verbal tactics such as verbal pressuring behavior, expressions of anger, threats to the relationship, et 
cetera. Rape is defined as any type of sexual intercourse obtained via incapacitation, physical force, or threats of physical force.

Measurement strategies. The specific measure used as well as any reported modifications to the measure were coded. We used data obtained during the piloting procedure to create a list of nine common modifications and coded these [changes to instructions/response scale (putting tactics first, using a frequency response scale), adding alcohol/substance items, adding sexual outcome items (such as gang rape), adding verbal coercion items, dropping items, unclear additions, adding follow-up items regarding context (such as relationship to perpetrator), revising items to gender neutral, and combining items].

\section{Results}

\section{Descriptive Findings}

Data from 25,524 participants representing 78 independent samples published from 20002017 were reviewed. Of the 78 independent samples, one of these was a study that randomly assigned participants to two different forms of a sexual perpetration assessment tool; these experimental conditions were generally treated as two separate studies (Abbey et al., 2005); thus, the 77 citations listed in Figure 1. An additional two studies were identified which utilized two different questionnaires to assess sexual perpetration, with one questionnaire being the primary questionnaire and the second questionnaire being used to assess validity (Johnson, Murphy, \& Gidycz, 2017; Strang, Peterson, Hill \& Heiman, 2013). For these studies, the primary questionnaire and prevalence rates were included in analyses while the secondary questionnaire was excluded to not violate assumptions of independence needed for statistical analyses. This dataset is publicly available through the Mendeley website (Anderson, 2018). 
The median year of publication was 2010, and the modal year was $2016(n=9)$. Year of publication was not significantly related to the mean prevalence rate. Most of the studies represented convenience samples of college students (92.3\%), although a small number represented a sample recruited based on a specific risk factor such as fraternity membership or alcohol consumption patterns. Most studies (94.9\%) reported data on the number of racial and ethnic minorities included as participants; the average percent of the sample that identified as racial or ethnic minorities was 23.2\% (SD = 17.4). Approximately two-thirds of samples reported data on the number of participants who identified as sexual minorities; the mean percent of sexual minorities included was $2.5 \%(\mathrm{SD}=3.6)$. Zero studies reported including any gender minorities.

\section{Prevalence}

Overall prevalence. We limited our analysis of overall prevalence rates to studies that assessed multiple types of sexual perpetration. In other words, the overall prevalence rate reflected the number of participants who reported any type of sexual violence perpetration, ranging from the least (e.g., unwanted sexual contact) to most severe (e.g., rape). For the 68 studies that computed this comprehensive score, the prevalence rate of any type of sexual perpetration ranged from 6.7 - 92.0\%, average prevalence rate of 29.3\% (SD = 16.8\%), and median of $25.0 \%$.

Prevalence of verbal coercion. Fifty-one studies reported rates of verbal coercion perpetration. The reported prevalence of verbal coercion perpetration ranged from $4.5-49.3 \%$; the average reported rate was $19.0 \%(\mathrm{SD}=12.6 \%)$ with a median of $15.8 \%$. 
Prevalence of rape. Forty-five studies reported a prevalence rate specific to rape perpetration. The reported prevalence of rape perpetration ranged from $0.0-29.2 \%$; the average rate reported was $6.5 \%(\mathrm{SD}=6.3 \%)$ with a median of $4.8 \%$.

Prevalence of acknowledged rape. A small number of studies reported rape acknowledgment (i.e., the number of participants who responded affirmatively to the question, “Do you think you may have ever raped someone?” rather than a behaviorally specific item regarding rape). Only three studies reported these data (Ambrose \& Gross, 2016; Anderson, Cahill, Delahanty, 2017; Sutherland, Amar \& Sutherland, 2014); rates of acknowledged rape perpetration in the sample ranged from $0.4-1.5 \%$ with a mean rate of $0.9 \%$.

Comparison to prior reviews. The present results are largely consistent with prior sexual perpetration prevalence rates. Spitzberg (1999) found an overall prevalence rate of approximately $25 \%$ while the average prevalence rate in this study was $29.3 \%$. Spitzberg found the average prevalence rate for rape was $4.7 \%(\mathrm{SD}=5.1)$ while this study found $6.5 \%$ (SD = 6.3). Because of the dominance of studies using the SESs in both the study by Spitzberg (1999) and the current sample, we calculated average prevalence rates for studies that used the SES vs. studies that did not use the SES (see Table 1). Further, in analyzing non-SES-using studies, we only analyzed studies that did not use the SES and used a questionnaire that was standardized or semi-standardized. We use the term standardized to mean evidence of validity and reliability has been documented in the literature and semi-standardized to mean evidence of validity or reliability has been documented in the literature.

These analyses revealed large differences such that non-SES-using studies found consistently higher prevalence rates for all perpetration categories. Specifically, the overall prevalence rate for studies using versions of the SES was 26.2\%, whereas the rate for studies 
using non-SES measures was $41.5 \%$. For verbal coercion, the rate for studies using the SES was $17.8 \%$, while the prevalence rate was $26.5 \%$ for non-SES-using studies. For the prevalence of rape, the average prevalence rate was $5.0 \%$ for studies using SES versions and $10.5 \%$ for studies using non-SES measures. The difference in prevalence rates between SES-using and non-SESusing studies was statistically significant for all three types of sexual perpetration, $p<.0001$.

\section{Measurement Strategies}

Descriptive Findings. Across the 78 studies reviewed, at least 16 different sexual perpetration questionnaires were reported, not including modifications made to the SESs (see Table 2). Of these 16 questionnaires, eight were standardized or semi-standardized. All were one-stage type strategies. By far the most common measure used was the 1982 SES; 30 studies used this measure. Also popular were the 1987 SES (20 uses), and the SES-SFP (8 uses); thus, variations of the SESs were the dominant measurement strategy. Altogether, the SESs (and their modifications) accounted for $78.2 \%$ of the measures used. Table 2 lists the standardized and semi-standardized questionnaires used, prevalence rate identified by each questionnaire, and their frequency of use.

\section{Effects of questionnaire type for overall sexual perpetration.}

First, we tested whether prevalence rates using the most recent SES (the SES-SFP) were comparable to other available measures of sexual perpetration by computing chi-square tests. We focused on the SES-SFP as the comparison point, given the predominance of the SESs as a measurement strategy and the SES-SFP as the most up-to-date iteration. We only compared the SES-SFP to other measures that had at least three samples or a summed $\mathrm{N}$ of $>1000$.

The SES-SFP (19.8\%) detected significantly lower prevalence rates than the 2005 SES, as modified by Abbey et al. 2005 (29.0\%), the Post-Refusal Persistence Scale family of 
questionnaires (36.9\%), the Revised Conflicts Tactics Scale - Sexual Coercion Subscale (38.6\%), and the Tyler et al. 6-item scale family of questionnaires (46.4\%), $p<.0001$. However, the SES-SFP was statistically equivalent to the 1987 standard SES (20.2\%) and the 1982 standard SES (21.4\%). For further details, see Table 2.

Effects of questionnaire type on verbal coercion prevalence rates. We compared the use of specific questionnaires on prevalence rates related to verbal coercion, see Table 3. We did not include investigator-created measures as a comparison because this category of measure rarely specified sub-types of sexual perpetration. Using the standard SES-SFP as a comparison to other standardized measures, the SES-SFP (10.2\%) detected lower rates of verbal coercion than the 1982 standard SES (16.0\%), the 1987 standard SES (14.5\%), the 2005 SES as modified by Abbey et al. 2005 (17.1\%) and the Tyler 6-item family of questionnaires (20.1\%).

Effects of questionnaire type on rape prevalence rates. We also compared the use of the SES-SFP to other measures for prevalence rates of rape specifically (see Table 3). We did not include investigator-created measures as a comparison because rarely did this category of measure specify sub-types of sexual perpetration. Further, comparing the standard SES-SFP to other measures revealed that the SES-SFP detected higher rates of rape than the 1982 standard SES (7.2\% versus 4.8\%), the 1987 standard SES (5.0\%), and the SES as modified by Abbey et al. 2005 (4.6\%). However, the standard SES-SFP detected lower rates of rape than the Tyler standard 6-item family of questionnaires (15.0\%).

\section{Tests of specific modifications.}

We assessed the effects of questionnaire modifications in two ways, somewhat analogous to within vs. between group analyses. First, we compared the modified versions of questionnaires 
to the standardized versions of that same questionnaire (modifications within questionnaire type). Secondly, we tested the effects of specific types of modifications across questionnaires.

Modified vs. standardized questionnaires (within questionnaire). Most of the time, researchers opted to modify standardized questionnaires; $61.1 \%(n=44)$ of the 72 independent samples that used standardized or semi-standardized questionnaires were modified in some way. This also extended to use of the SESs; the SESs were modified in $63.8 \%$ of the studies using a version of the SES measures. Differences between modified vs. un-modified questionnaires were tested only when there were at least 3 samples in each category; thus, we were only able to compare modified SESs to standard SESs.

Modified vs. standardized questionnaires: overall sexual perpetration. For each version of the SESs (1982, 1987, and SES-SFP), the modified versions detected significantly higher prevalence rates than the standard version, $p \leq .001$, (see Table 2 ) for overall sexual perpetration. The largest discrepancy was for the 1982 SES $(11.2$ points, $p<.0001)$ and the smallest discrepancy was for the SES-SFP (5.8 points, $p<.001)$.

Modified vs. standardized questionnaires: verbal coercion. Results for verbal coercion were similar to those of overall prevalence rates; modified versions of each of the SESs (1982, 1987, and the SES-SFP) produced higher prevalence rates for verbal coercion. Specifically, the largest discrepancy was between the modified SES-SFP and the standard SES-SFP (12.5 points, $p<.0001)$ and the smallest discrepancy was between the modified 1987 SES and the standard 1987 SES (3 points, $p<.0001)$.

Modified vs. standardized questionnaires: rape perpetration. Analyses were repeated for rape perpetration; however, we found a different pattern for rape perpetration, see Table 4. Only the standard version of the SES-SFP detected higher prevalence rates than the modified version 
of the SES-SFP (differences of 2.7 points, $p=.007$ ). Meanwhile, the modified and standard 1982 and 1987 SESs detected statistically equivalent rape perpetration prevalence rates.

Tests of specific modification types (between questionnaires). We identified 81 modifications. On average, studies that modified measures incorporated 1.1 modifications $(\mathrm{SD}=$ 1.3), range $=1-5$. We identified nine possible modifications, the most common modifications were changes to the instructions/response scale (25.9\% of modifications) and adding alcohol/substance use items (19.8\% of modifications). The least common were combining items (2.5\%) and editing items to use gender neutral language (6.2\%). A table summarizing all modifications identified and their frequency is available as supplemental material on the first author's website.

Next, we tested the effects of specific types of modifications by comparing prevalence rates for each type of modification across all standardized and semi-standardized questionnaires, see Table 4 . We only tested modifications that occurred at a frequency greater than $10 \%$ of the studies reviewed ( $n \geq 8$ ); using this cutoff, there were four types of modifications tested. Changes to the instructions or response format increased prevalence rates for overall sexual perpetration (27.6\% vs. 33.1\%, $p<.0001)$, and rape $(5.4 \%$ vs. $6.4 \%, p=.009)$, but had no effect for verbal coercion (19.9\% vs. 20.1\%). Adding alcohol and/or substance use items increased prevalence rates for overall sexual perpetration $(27.1 \%$ vs. $36.8 \%, p<.0001)$, but had the opposite effect for rape (6.6\% vs. $4.7 \%, p=.001)$ and verbal coercion $(20.4 \%$ vs. $18.4 \%, p=$ .002). Adding verbal coercion items uniformly increased prevalence rates; the largest difference was for overall sexual perpetration (26.8\% vs. 46.2\%, $p<.0001)$. However, verbal coercion (19.5\% vs. $24.5 \%, p<.0001$ and rape perpetration were similarly affected (5.7\% vs. 10.2\%, $p<$ .0001). Finally, adding sexual outcome items increased prevalence rates for overall sexual 
perpetration $(26.9 \%$ vs. $43.5 \%, p<.0001)$ and verbal coercion $(19.4 \%$ vs. $23.3 \%, p<.0001)$ but had no effect on rape prevalence rates (6.1 vs. 6.2\%).

\section{Discussion}

This study sought to fill a critical gap in the literature - determining the prevalence rate of sexual perpetration in college men. In the absence of epidemiological data, our study aggregated the findings of approximately 25,000 college men across 78 independent samples. Unlike prior research on this topic, we also assessed the extent to which differing measurement strategies impacted prevalence rates to examine explanations for why prevalence rates vary. Table 5 summarizes key findings in this paper.

\section{Prevalence Rate Findings}

The average rate of sexual violence perpetration of any type, from studies that assessed multiple types of perpetration behavior was $29.3 \%(S D=16.8)$. However, there was an enormous range of rates reported: $6.7-92.0 \%$. The highest values in this range came from a study that defined and assessed a very broad range of sexual perpetration behavior (Thompson \& Cracco, 2008). The next values were in the 60s and came from studies using tactic first questionnaires and/or added items. For verbal coercion, we found an average rate of 19.0 (SD = 12.6) with a range of $4.5-49.3 \%$. For rape, we found an average prevalence rate of $6.5 \%$ (SD = 6.3) with a range of $0-29.2 \%$. We also found that rates of acknowledged perpetration in the samples hovered around $1.0 \%$ or less; however, very few studies reported this statistic.

These data are largely consistent with the only identified prior review (Spitzberg, 1999) that reported an overall perpetration rate of $25.0 \%$ and a prevalence rate for rape of $5.0 \%$. However, the average rate of $25 \%$ is clearly tied to the use of the SES. When comparing SESusing to non-SES-using studies our findings are quite different; the average rate of perpetration 
for non-SES-using studies was $41.5 \%$ and for rape the prevalence rate was $10.5 \%$, nearly twice as high as the SES rates observed in this review and as the rates reported by Spitzberg (1999) 5.0\%. This indicates that same measurement tools have been in use for the last 30 years. To use Hamby (2014)'s language, the technology used to understand violence has stagnated and is clearly in need of innovation. There is a serious need for research to develop new and innovative tools including qualitative research to understand the boundaries of our constructs, how participants understand behaviorally specific language, and how participants understand their own behavior. In addition, too often frequent use has stood in for understanding the actual psychometric properties of our measures (as noted by Hamby, 2014). Finally, large scale, national, epidemiological research on sexual perpetration is needed to better estimate the prevalence of this critical health behavior. Considering the immense damage caused by sexual perpetration, the current scientific state of measurement is unacceptable.

\section{Effects of Specific Questionnaires on Prevalence Rates}

A number of questionnaires consistently produced higher prevalence rates than the standard SES-SFP, including the 2005 SES as modified by Abbey et al., the Post-Refusal Sexual Persistence Scale family of measures, the Revised Conflicts Tactics - Sexual Coercion subscale, the Tyler 6 items, and the Coercive Sexuality Scale. Notably, all of these questionnaires use a tactic first design for all or most of the items (in contrast to the SES-SFP), and many of them used a frequency scale response format that encompassed a very broad range. Anderson et al., (2018) and Strang et al., (2013) discuss how tactic-first items, frequency scales, item order, questionnaire structure, and the assessment of consent may all be related to differences in prevalence rates obtained by measures of sexual perpetration. One of the major challenges to this literature is that different measures produce different prevalence rates, but it is unclear if one or 
more of these questionnaires is the "best" or gold standard questionnaire. Only multiple empirical tests, including the Cronbach \& Meehl (1955) approach to construct validity, construct validity interviews in the manner of Peterson \& Strang (2017), and reliability testing, can indicate which questionnaire has empirical support for specific populations and under specific circumstances.

We also compared the standard SES-SFP to the standard 1982 and 1987 SES measures. Interestingly, the standard SES-SFP did not always produce higher prevalence rates than the older SESs, in spite of assessing a much larger range of perpetration behavior. In terms of detecting overall levels of sexual perpetration, the standard SES-SFP was statistically equivalent to the 1982 and 1987 SESs. However, the standard SES-SFP detected lower rates of verbal coercion but higher rates of rape than both the standard 1982 and 1987 SES. This may be related to Strang and Peterson's (2017) finding that men consider the SES-SFP verbal coercion items so long as to be confusing and therefore may disengage from answering these items (Hamby \& Ickes, 2015; Swain, Weathers \& Niedrich, 2008). Thus, the more comprehensive approach of the SES-SFP may only be effective for detecting cases of rape perpetration.

Most sexual perpetration measures have not been submitted to as rigorous validity and reliability testing as the 1982 SES. While the 1982 SES demonstrated strong evidence of validity (Koss \& Gidycz, 1985), interview research using items from the SES-Long Form Perpetration (which has overlapping item content with the SES-SFP) indicated a significant level of false negatives; false negatives were identified for 34/34 participants interviewed and varied in several ways (Strang \& Peterson, 2017). Meanwhile, the Post-Refusal Sexual Persistence Scale shows good evidence of construct validity in one study (Struckman-Johnson, Anderson, StruckmanJohnson, \& Smeaton, in press) and as a revised questionnaire in another (Strang \& Peterson, 
2017), but there is no available evidence regarding test-retest reliability. For many of the remaining questionnaires, only convergent validity has been evaluated (Tyler 6 items: Tyler, Hoyt, \& Whitbeck, 1988; Coercive Sexuality Scale: Rapaport \& Burkhart, 1984).

To our knowledge, test-retest reliability data are only available for the 1982 SES, the SES-SFP, and the Revised Conflict Tactics Scales (CTS2). We emphasize test-retest reliability rather than internal consistency as test-retest reliability is a stronger and more relevant test of reliability for behavioral measures (Koss et al., 2007). Further, the available test-retest data suggest room for improvement. The correlation between CTS2 scores among court-ordered domestic violence treatment seekers was $r=.30$ for the sexual violence subscale over an interval of nine weeks (Vega \& O’Leary, 2007). For the SES-SFP, the evidence of two-week test-retest reliability is stronger (82-91\% agreement), but it is based on two small samples of college men (N $\approx 70$ : Anderson et al., 2017; Johnson et al., 2017). While Koss and Gidycz (1985) showed strong evidence of test-retest reliability for the 1982 standard SES, these data are now 30+ years old and should not be generalized to the 1987 SES or the SES-SFP.

Indeed, preliminary data on the SES-SFP indicates it has different psychometric properties than the 1982 SES. Estimates of test-retest agreement are similar for the 1982 SES and the SES-SFP; yet because of the extremely small samples used to test the SES-SFP, these results should be interpreted with caution. The test-retest kappa values (which adjust for chance agreement) are in the weak to moderate range for the SES-SFP, indicating that $4-63 \%$ of the data are coded reliably (Anderson et al., 2017; Johnson et al., 2017); this range is well below clinical standards (McHugh, 2012). Further, convergent validity correlations have reflected generally weak relationships; $r=.14-34$ between SES-SFP scores and a range of relevant constructs, including measures of rape myth acceptance and intimate partner violence 
perpetration (Anderson et al., 2017; Davis et al., 2014). These differences may not be especially surprising given how different the two questionnaires are; the SES-SFP has nearly triple the number of items as the 1982 SES and assesses a much larger range of potential coercive tactics with greater specificity in sexual acts. However, in terms of recommending a specific instrument, the psychometric properties of the SES-SFP and the 1982 SES have been the subject of far more published empirical reports than many of the non-SES measures identified in this review. Thus, investigators are forced to weigh the pros/cons of a limited literature in selecting instruments.

\section{Modifications to Existing Measures}

Although the SESs appear to be the most common measures used in the literature, in reality, the SESs were modified most of the time they were used (63.3\%), confounding the ability to explicitly and directly link modifications with prevalence rates. Interestingly, in general, modifying the SESs increased prevalence rates compared to the standard versions of the SES. Further, certain modifications were consistently associated with higher prevalence rates namely, adding items and changing the instructions/response format from dichotomous to a frequency scale. Notably, these relationships were complicated; some specific types of modifications (e.g., adding alcohol/substance use items) increased overall prevalence rates while decreasing verbal coercion and rape prevalence rates. Modifications such as using a frequency scale response format appear to increase prevalence rates, especially when considering literature

from other fields such as intimate partner violence (Dietz \& Jasinski, 2007; Hamby, Sugarman \& Boney-McCoy, 2006); it is likely that this design feature facilitates de-stigmatization and thus greater disclosure. Adding verbal coercion items and sexual outcome items uniformly increased prevalence rates; it is unclear why the same was not true for adding alcohol/substance use items. Many of the studies that added alcohol and substance use items combined these, assessing the 
use of alcohol and other substances within the same item. Perhaps this combination increased the length or complexity of these items beyond optimal levels. However, a looming question is whether these modifications to standardized measures are valid and reliable; rarely did researchers test the effects of these modifications or report the psychometric properties of these modified measures.

\section{Limitations}

Despite our thorough screening process of nearly 1000 pieces of literature in two databases, it is possible that we missed important studies, given the wide diversity of language and keywords in this area of research. We did not report or record prevalence rates related to shorter periods of time; we chose rather to focus on the "lifetime" time-frame for clarity of comparison amongst studies. We also chose to focus exclusively on college men given that prior research focused strongly on college women's experiences of victimization -and focusing on a single population for the first study of this nature increased the strength of our inferences. We were unable to include a focus on local cultural factors that undoubtedly influence perpetration (e.g., campus attitudes towards alcohol, fraternities, gender equality). We also did not code prevalence rates specific to unwanted sexual contact - though research such as Thompson and Cracco (2008) indicate that this behavior may be extremely common in certain settings. Finally, it was often assumed in the literature (and even at times perhaps inadvertently within this article) that men were always the perpetrators and women the victims; indeed, some investigators $(n=5)$ chose to modify the language of the measures to be more gender-neutral and challenge this stereotype. We encourage this trend, particularly given the empirical support for gender-neutral questionnaires (Anthony \& Cook, 2012), and we also recommend that the research becomes more inclusive of gender and sexual minorities. While all studies included reported on the 
number of racial and ethnic minority participants, only $66 \%$ reported on the number of sexual minority participants and zero studies included any gender minority participants. Research clearly indicates gender and sexual minorities are at much greater risk for experiencing sexual victimization (Rothman, Exner, \& Baughman, 2011). Yet, available measures, even those designed to be more gender neutral (e.g., the SES-SFP), may contain unwitting heterosexist and gender bias (Anderson, Cahill, \& Delahanty, 2018) that hinders further research with these populations. Finally, we came across few, if any, studies in our review that examined the sexual orientation of the target of perpetration behavior (e.g., the victim) - an area for future research.

\section{Clinical Practice and Policy Implications}

The present results speak to the widespread prevalence of sexual violence perpetration by college men in US and Canadian society and perhaps an over-focus on victimization in prior research. For clinicians working with individual men, we recommend routine screening and assessment for perpetration and perpetration-related risk factors (e.g., alcohol abuse, rigid sexual/gender attitudes, impersonal sex). It is highly likely that much of the behavior men consider normal for themselves or their peers are in fact facilitative of violence; the data reported here on acknowledged perpetration are consistent with this.

Very few studies reported rates of acknowledged perpetration, yet this construct and associated statistics highlight an ongoing challenge for the development of sexual perpetration prevention programs. The extraordinarily low rates of perpetration acknowledgement suggest that many rape perpetrators likely do not perceive their behavior to be criminal or violent. Yet, data suggest that college men are capable of recognizing perpetration behavior in their peers. In one large, random sample using a questionnaire based on the SES, $44.8 \%$ of college men reported knowing someone who had perpetrated any form of sexual violence (Sorenson, Joshi, \& Sivitz, 2014). Experimental research has found that men with histories of sexual perpetration 
view their behavior as typical and appropriate compared to other men (Loh, Orchowski, Gidycz, \& Elizaga, 2007). That is, men who perpetrate sexual violence do not view their behavior as harmful and inappropriate. This highlights a potential point for intervention - specifically, creating interventions that can leverage theory (social judgment theory, cognitive dissonance) to alter an individual male’s perceptions of their own perpetration behavior. Basic cognitivebehavioral theory and interventions often suggest first monitoring behavior in order to change it - thus, devising ways to encourage men to recognize their perpetration behavior is important. Changes in recognition of perpetration behavior is also an important outcome variable for related interventions, such as bystander programs. Following, better understanding the mechanism of this disconnect could potentially impact multiple levels and types of interventions to reduce rape.

For those working with individuals who have been sexually victimized, our data speak to the unfortunately normative nature of their experiences; yet, perhaps these results can help challenge cognitions of self-blame by those who have been victimized by demonstrating the high prevalence of perpetration. Finally, it is hoped that the present results inspire policy change, as more resources are needed to prevent sexual violence and that begins with preventing perpetration, not victimization. This is not to say we wish to decrease or challenge the resources available to those who have been harmed, but rather that we need to increase investment in understanding and preventing sexual violence perpetration. Particularly, research designed to understand how to change and prevent perpetration behavior is sorely needed (Gidycz, 2011). Key implications and recommendations are summarized in Table 6.

\section{Future Research}

The present review underscores the extreme need for measurement research on sexual perpetration questionnaires, greater consistency in measurement strategies in future research, and 
greater transparency in reporting measurement strategies. Many of the issues raised in this article are empirical questions that could be answered through research collaboration and consortia. Indeed, many of these empirical questions were first raised by Koss et al., (2007) when the SESSFP was published. In the past, this field has benefited from such approaches - the SES-SFP and its partner questionnaires were forged in such collaboration (Koss et al., 2007). Yet, there seems to have been little to no ongoing collaboration in terms of investigating the uses and psychometric properties of the revised SES-SFP or other available measures.

One possible reason for the lack of cohesion in measurement and methods may be the relative youth of this area of literature, the interdisciplinary nature of the research, and the varied needs/goals of the researchers. Related to this, in addition to greater transparency in measurement, the present findings also underscore the need for clarity in defining terms used in research. Terms like “sexual aggression”, “sexual coercion”, and “sexual assault” are often presumed to be talking about victimization when in fact, these terms refer to a specific incident that could be victimization or perpetration depending on the perspective taken. We also strongly encourage researchers to report basic descriptive data in their research. These recommendations echo the principles of good practice for studying youth sexual aggression elaborated by Krahé \& Vanwesenback (2015), and we join them in highlighting these issues for the field as well as this project. We excluded many interesting and meaningful studies because perpetration was used as an outcome variable and the prevalence rate was not reported.

\section{Conclusions}

Estimates of the true prevalence of sexual violence perpetration in college men are limited by the lack of large-scale, national, epidemiological studies on this issue and the high variability in measurement strategies and methodological procedures in the current literature. 
Though we found an overall prevalence rate of approximately $29 \%$, this is strongly associated with measurement strategy and may be an over- or underestimate. We strongly recommend that future research report measurement strategies and procedures with greater transparency and provide basic descriptive statistics. Our results provide strong evidence of the widespread nature of sexual violence perpetration on college campuses and the need for greater resources to understand and prevent this behavior that undermines the health and safety of so many people. 


\section{References}

Abbey, A., Parkhill, M. R., \& Koss, M. P. (2005). The effects of frame of reference on responses to questions about sexual assault victimization and perpetration. Psychology of Women Quarterly, 29(4), 364-373. https://doi.org/10.1111/j.1471-6402.2005.00236.x

Abbey, A. (2005). Lessons learned and unanswered questions about sexual assault perpetration. Journal of Interpersonal Violence, 20, 39-42.

Ambrose, C. E., \& Gross, A. M. (2016). Interpreting Sexual Dating Encounters: Social Information Processing Differences in Men and Women. Journal of Family Violence, 31(3), 361-370. https://doi.org/10.1007/s10896-015-9757-z

Anderson, R. E., (2018). Dataset: The Frequency of Sexual Perpetration in College Men, Reported Prevalence Rates from 2000-2017”, Mendeley Data, v1. doi:10.17632/fy2352pn3r.1

Anderson, R. E., Cahill, S. P., \& Delahanty, D. L. (2017). Initial Evidence for the Reliability and Validity of the Sexual Experience Survey-Short Form Perpetration (SES-SFP) in College Men. Journal of Aggression, Maltreatment \& Trauma.

https://doi.org/10.1080/10926771.2017.1330296

Anderson, R. E., Cahill, S. P., \& Delahanty, D. L. (2018). Discordance Between the Sexual Experiences Surveys-Short Forms and the Revised Conflict Tactics Scales in College Men. Psychology of Violence. https://doi.org/10.1037/vio0000199

Anthony, E. R., \& Cook, S. L. (2012). Assessing the impact of gender-neutral language on disclosure of sexual violence. Psychology of Violence, 2(3), 297-307. https://doi.org/10.1037/a0028562

Basile, K. C., Smith, S., Breiding, M. J., Black, M. C., \& Mahendra, R. (2014). Sexual Violence 
Surveillance: Uniform Definitions and Recommended Data Elements, Version 2.0. Atlanta, GA. Retrieved from https://www.cdc.gov/violenceprevention/pdf/sv_surveillance_definitionsl-2009-a.pdf Black, M. C., Basile, K. C., Breiding, M. J., Smith, S., Walters, M. L., Merrick, M., ... Stevens, M. (2011). The National Intimate Partner and Sexual Violence Survey (NISVS): 2010 Summary Report. Atlanta, GA, USA.

Bouffard, L., \& Goodson, A. (2017). Sexual coercion, sexual aggression, or sexual assault: How measurement impacts our understanding of sexual violence. Journal of Aggression, Conflict and Peace Research, 9, 269-278.

Breiding, M. J., Basile, K. C., Smith, S., Black, M. C., \& Mahendra, R. (2015). Intimate Partner Violence Surveillance: Uniform Definitions and Recommended Data Elements, Version 2.0. Atlanta, GA, USA.

Buday, S. K., \& Peterson, Z. D. (2015). Men's and Women's Interpretation and Endorsement of Items Measuring Self-Reported Heterosexual Aggression. Journal of Sex Research, 52(9), 1042-1053. https://doi.org/10.1080/00224499.2014.967373

Cantor, D., Fisher, B., Chibnall, S., Townsend, R., Lee, H., Bruce, C., ... Inc., W. (2015). Report on the AAU Campus Climate Survey on Sexual Assault and Sexual Misconduct. Washington, DC, USA. https://doi.org/10.1016/j.aqpro.2013.07.003

Cook, S. L., Gidycz, C. A., Koss, M. P., \& Murphy, M. (2011). Emerging Issues in the Measurement of Rape Victimization. Violence Against Women, 17(2), 2012-2018. https://doi.org/10.1177/1077801210397741

Davis, K. C., Gilmore, A. K., Stappenbeck, C. A., Balsan, M. J., George, W. H., \& Norris, J. (2014). How to Score the Sexual Experiences Survey? A Comparison of Nine Methods. 
Psychology of Violence, 4(4), 445-461. https://doi.org/10.1037/a0037494

Dietz, T. L., \& Jasinski, J. L. (2007). The effect of item order on partner violence reporting: An examination of four versions of the revised Conflict Tactics Scales. Social Science Research. Retrieved from http://journals.ohiolink.edu/ejc/article.cgi?issn=0049089x\&issue=v36i0001\&article=353_te oioootrcts

Fedina, L., Holmes, J. L., \& Backes, B. L. (2018). Campus Sexual Assault: A Systematic Review of Prevalence Research From 2000 to 2015. Trauma, Violence, \& Abuse, 19(1), 76-93. https://doi.org/10.1177/1524838016631129

Fisher, B. S., Cullen, F. T., \& Turner, M. G. (2000). The Sexual Victimization of College Women. Washington, DC, USA.

Gidycz, C. A. (2011). Sexual revictimization revisited: A commentary. Psychology of Women Quarterly, 35, 355-361.

Hamby, S. (2014). Intimate Partner and Sexual Violence Research: Scientific Progress, Scientific Challenges, and Gender. Trauma, Violence, and Abuse. doi.org/10.1177/1524838014520723

Hamby, T., \& Ickes, W. (2015). Do the readability and average item length of personality scales affect their reliability? Some meta-analytic answers. Journal of Individual Differences, 36(1), 54-63. https://doi.org/10.1027/1614-0001/a000154

Hamby, S. L., \& Koss, M. P. (2003). Shades of Gray: A Qualitative Study of Terms Used in the Measurement of Sexual Victimization. Psychology of Women Quarterly, 27(3), 243-255. https://doi.org/10.1111/1471-6402.00104 
Hamby, S., Sugarman, D. B., \& Boney-McCoy, S. (2006). Does questionnaire format impact reported partner violence rates?: An experimental study. Violence and Victims, 21(4), 507518. https://doi.org/10.1891/vivi.21.4.507

Johnson, S. M., Murphy, M. J., \& Gidycz, C. A. (2017). Reliability and validity of the Sexual Experiences Survey - Short Forms victimization and perpetration. Violence and Victims, 32(1), 78-92. https://doi.org/10.1891/0886-6708.VV-D-15-00110

Kilpatrick, D. G., Resnick, H. S., Ruggiero, K. J., Conoscenti, L. M., \& McCauley, J. (2007). Drug-facilitated, Incapacitated, and Forcible Rape: A National Study. Charleston, SC: Medical University of South Carolina. Retrieved from http://www.ncjrs.gov/pdffiles1/nij/grants/219181.pdf

Kolivas, E. D., \& Gross, A. M. (2007). Assessing sexual aggression: Addressing the gap between rape victimization and perpetration prevalence rates. Aggression and Violent Behavior, 12(3), 315328. https://doi.org/10.1016/j.avb.2006.10.002

Koss, M. P. (1993). Rape: Scope, impact, interventions, and public policy responses. American Psychologist, 48, 1062-1069. https://doi.org/10.1037/0003-066X.48.10.1062

Koss, M. P., Abbey, A., Campbell, R., Cook, S., Norris, J., Testa, M., ... White, J. (2007). Revising the SES: A Collaborative process to improve assessment of sexual aggression and victimization. Psychology of Women Quarterly, 31, 357-370. https://doi.org/10.1111/j.1471-6402.2007.00385.x

Koss, M. P., \& Gidycz, C. A. (1985). Sexual Experiences Survey: Reliability and validity. Journal of Consulting and Clinical Psychology, 53, 422-423. https://doi.org/10.1037/0022006X.53.3.422

Koss, M. P., Gidycz, C. A., \& Wisniewski, N. (1987). The scope of rape: Incidence and 
prevalence of sexual aggression and victimization in a national sample of higher education students. Journal of Consulting and Clinical Psychology, 55, 162-170. Retrieved from http://psycnet.apa.orgjournals/ccp/55/2/162

Krahé, B., Haas, S., Vanwesenbeeck, I., Bianchi, G., Chliaoutakis, J., Fuertes, A., ... Zygadlo, A. (2016). Interpreting Survey Questions About Sexual Aggression in Cross-Cultural Research: A Qualitative Study with Young Adults from Nine European Countries. Sexuality \& Culture, 20, 1-23. https://doi.org/10.1007/s12119-015-9321-2

Krahé, B., \& Vanwesenbeeck, I. (2015). Mapping an agenda for the study of youth sexual aggression in Europe: assessment, principles of good practice, and the multilevel analysis of risk factors. Journal of Sexual Aggression, 2600, 1-16. https://doi.org/10.1080/13552600.2015.1066885

Krebs, C. P., Barrick, K., Lindquist, C. H., Crosby, C. M., Boyd, C., \& Bogan, Y. (2011). The Sexual Assault of Undergraduate Women at Historically Black Colleges and Universities (HBCUs). Journal of Interpersonal Violence, 26, 3640-3666. https://doi.org/10.1177/0886260511403759

Krebs, C. P., Lindquist, C. H., Warner, T. D., Fisher, B. S., \& Martin, S. L. (2007). The Campus Sexual Assault (CSA) Study Final Report. Washington, DC.

Krebs, C., Lindquist, C., Planty, M., Langton, L., Berzofsky, M. E., Asefnia, N., ... Enders, K. (2017). Sensitivity of Sexual Victimization Estimates to Definitional and Measurement Decisions. Journal of Interpersonal Violence, 088626051774419. https://doi.org/10.1177/0886260517744190

Liberati, A., Altman, D. G., Tetzlaff, J., Mulrow, C., Gøtzsche, P. C., Ioannidis, J. P., ... \& Moher, D. (2009). The PRISMA statement for reporting systematic reviews and meta- 
analyses of studies that evaluate health care interventions: explanation and elaboration. PLoS medicine, 6(7), e1000100.

Loh, C., Orchowski, L. M., Gidycz, C. A., \& Elizaga, R. A. (2007). Socialization and sexual aggression in college men: The role of observational influence in detecting risk cues. Psychology of Men \& Masculinity, 8(3), 129. https://doi.org/10.1037/1524-9220.8.3.129

McHugh, M. L. (2012). Interrater reliability: the kappa statistic. Biochemia Medica, 22(3), 276282. Retrieved from http://www.ncbi.nlm.nih.gov/pmc/articles/PMC3900052/

Mendes, K., Ringrose, J., \& Keller, J. (2018). \# MeToo and the promise and pitfalls of challenging rape culture through digital feminist activism. European Journal of Women's Studies, 25, 236-246.

Muehlenhard, C. L., Peterson, Z. D., Humphreys, T. P., \& Jozkowski, K. N. (2017). Evaluating the One-in-Five Statistic: Women's Risk of Sexual Assault While in College. Journal of Sex Research. Taylor \& Francis. https://doi.org/10.1080/00224499.2017.1295014

Peterson, Z. D., Voller, E. K., Polusny, M. A., \& Murdoch, M. (2010). Prevalence and consequences of adult sexual assault of men: review of empirical findings and state of the literature. Clinical Psychology Review, 31(1), 1-24. https://doi.org/10.1016/j.cpr.2010.08.006

Quick, J. C., \& McFadyen, M. (2017). Sexual harassment: Have we made any progress? Journal of Occupational Health Psychology, 22(3), 286.

Rapaport, K., \& Burkhart, B. R. (1984). Personality and attitudinal characteristics of sexually coercive college males. Journal of Abnormal Psychology, 93(2), 216-221. https://doi.org/10.1037/0021-843X.93.2.216

Rothman, E. F., Exner, D., \& Baughman, A. L. (2011). The Prevalence of Sexual Assault 
Against People Who Identify as Gay, Lesbian, or Bisexual in the United States: A Systematic Review. Trauma, Violence, \& Abuse, 12(2), 55-66.

https://doi.org/10.1177/1524838010390707

Rueff, W. T., \& Gross, A. M. (2017). Assessing Sexual Coercion: Survey Wording Differences and the Victimization-Perpetration Discrepancy. Journal of Family Violence, 32(3), 325331. https://doi.org/10.1007/s10896-016-9859-2

Smith, P. H., Homish, G. G., Leonard, K. E., \& Cornelius, J. R. (2012). Intimate partner violence and specific substance use disorders: Findings from the National Epidemiologic Survey on Alcohol and Related Conditions. Psychology of Addictive Behaviors, 26, 236-245. https://doi.org/10.1037/a0024855

Spitzberg, B. H. (1999). An analysis of empirical estimates of sexual aggression victimization and perpetration. Violence and Victims, 14(3), 241-260.

Sorenson, S. B., Joshi, M., \& Sivitz, E. (2014). Knowing a Sexual Assault Victim or Perpetrator: A Stratified Random Sample of Undergraduates at One University. Journal of Interpersonal Violence, 29(3), 394-416. https://doi.org/10.1177/0886260513505206

Strang, E., \& Peterson, Z. D. (2017). Unintentional Misreporting on Self-Report Measures of Sexually Aggressive Behavior: An Interview Study. The Journal of Sex Research, 54(8), 113. https://doi.org/10.1080/00224499.2017.1304519

Strang, E., Peterson, Z. D., Hill, Y. N., \& Heiman, J. R. (2013). Discrepant responding across self-report measures of men's coercive and aggressive sexual strategies. Journal of Sex Research, 50(5), 458-469. https://doi.org/10.1080/00224499.2011.646393

Struckman-Johnson, C., Anderson, P. B., Struckman-Johnson, D., \& Smeaton, G. (in press). The Post-Refusal Sexual Persistence Scale. In R. Milhausen, J. K. Sakuluk, T. D. Fisher, C. M. 
Davis, \& W. Yarber (Eds.), Handbook of Sexuality-Related Measures (4th ed.). New York, NY, USA: Routledge.

Sutherland, J. L., Amar, A. F., \& Sutherland, M. A. (2014). Victimization and perpetration of sexual violence in college-aged men and women. Journal of Forensic Nursing, 10(3), 153159.

Swain, S. D., Weathers, D., \& Niedrich, R. W. (2008). Assessing Three Sources of Misresponse to Reversed Likert Items. Journal of Marketing Research, 45(1), 116-131. https://doi.org/10.1509/jmkr.45.1.116

Swartout, K. M., Koss, M. P., White, J. W., Thompson, M. P., Abbey, A., \& Bellis, A. L. (2015). Trajectory Analysis of the Campus Serial Rapist Assumption. JAMA Pediatrics, 169(12), 1148-1154. https://doi.org/10.1001/jamapediatrics.2015.0707

Tharp, A. T., DeGue, S., Valle, L. A., Brookmeyer, K. A., Massetti, G. M., \& Matjasko, J. L. (2013). A Systematic Qualitative Review of Risk and Protective Factors for Sexual Violence Perpetration. Trauma, Violence, and Abuse (Vol. 14). https://doi.org/10.1177/1524838012470031

The Bureau of Justice Statistics. (n.d.). National Crime Victimization Survey (NCVS). Retrieved August 9, 2018, from https://www.bjs.gov/index.cfm?ty=dcdetail\&iid=245

The White House Council on Women and Girls. (2014). Rape and Sexual Assault: A Renewed Call to Action. Washington, DC, USA. Retrieved from https://obamawhitehouse.archives.gov/sites/default/files/docs/sexual_assault_report_1-2114.pdf

Thompson, E. H., \& Cracco, E. J. (2008). Sexual Aggression in Bars: What College Men Can Normalize. The Journal of Men’s Studies, 16(1), 8296. https://doi.org/10.3149/jms.1601.82 
Turchik, J. A., \& Hassija, C. M. (2014). Female Sexual Victimization Among College Students: Assault Severity, Health Risk Behaviors, and Sexual Functioning. Journal of Interpersonal Violence, 29(13), 2439-2457. https://doi.org/10.1177/0886260513520230

Tyler, K. A., Hoyt, D. R., \& Whitbeck, L. B. (1998). Coercive Sexual Strategies. Violence and Victims, 13(1), 47-61.

Vega, E. M., \& O’Leary, K. D. (2007). Test-retest reliability of the revised Conflict Tactics Scales (CTS2). Journal of Family Violence. https://doi.org/10.1007/s10896-007-9118-7

Ybarra, M. L., Espelage, D. L., Langhinrichsen-Rohling, J., Korchmaros, J. D., \& Boyd, D. (2016). Lifetime Prevalence Rates and Overlap of Physical, Psychological, and Sexual Dating Abuse Perpetration and Victimization in a National Sample of Youth. Archives of Sexual Behavior, 45, 1083-1099. https://doi.org/10.1007/s10508-016-0748-9 
Figure 1

\section{PRISMA Flow Diagram of Search Strategy}

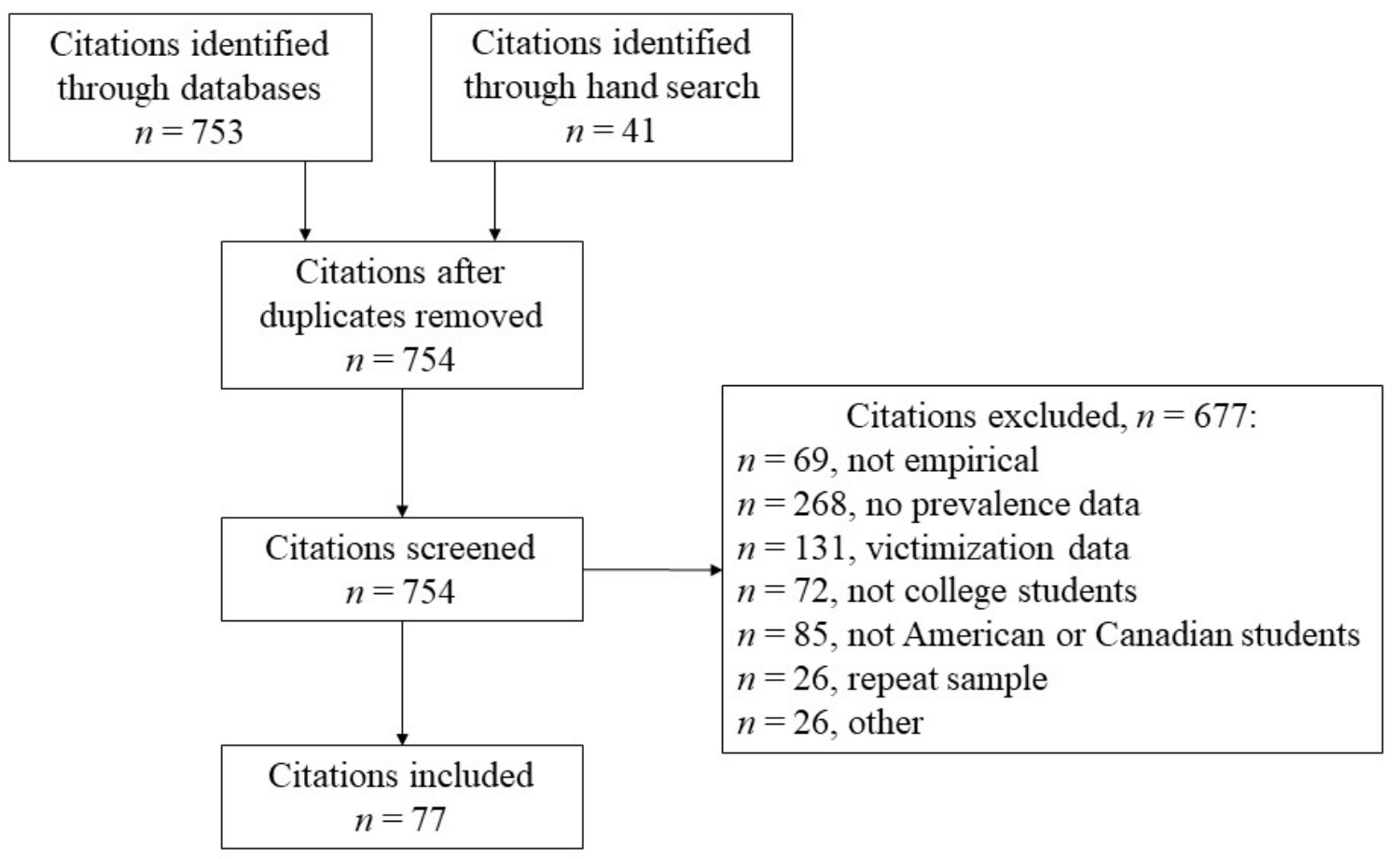


Table 1

Comparison of Average Prevalence Rates for SES and non-SES studies

\begin{tabular}{|c|c|c|c|c|}
\hline Studies & $\begin{array}{l}\text { Number studies; } \\
\text { summed } n\end{array}$ & $\begin{array}{l}\text { Mean, SD } \\
\text { All Sexual } \\
\text { Perpetration }\end{array}$ & $\begin{array}{l}\text { Mean, SD } \\
\text { Verbal Coercion }\end{array}$ & Mean, $S D$ Rape \\
\hline \multicolumn{5}{|l|}{ All studies } \\
\hline SESs: Yes & $n=60 ; 16,670$ & $25.9 \%(16.3)$ & $17.7 \%(11.7)$ & $5.0 \% \quad(4.4)$ \\
\hline SESs: No & $n=20 ; 9,382$ & $33.4 \%(17.2)$ & $22.2 \%(14.4)$ & $11.6 \%(9.0)$ \\
\hline \multicolumn{5}{|c|}{ Standardized subset* } \\
\hline SESs: Yes & $n=58 ; 16,142$ & $26.2 \%(16.4)$ & $17.8 \%(12.0)$ & $5.0 \% \quad(4.3)$ \\
\hline SESs: No & $n=14 ; 4,358$ & $41.5 \%(13.2)$ & $26.5 \%(14.3)$ & $10.5 \%(6.8)$ \\
\hline
\end{tabular}

Note. SES = Sexual Experiences Survey, any version; All comparisons between the SES-based vs. non-SES based study prevalence rates at $p<.0001$ for that type of perpetration. *Only studies using standardized or semi-standardized questionnaires, see above for further details. 
Table 2

Prevalence of Any Level of Sexual Perpetration by Measure Used and Statistical Comparisons

\begin{tabular}{|c|c|c|c|c|c|c|}
\hline \multirow[b]{2}{*}{ Measure } & \multirow[b]{2}{*}{$n$} & \multirow[b]{2}{*}{ Mean\% } & \multirow[b]{2}{*}{ Range \% } & \multirow[b]{2}{*}{ Summed n's } & \multicolumn{2}{|c|}{ Statistical Comparisons } \\
\hline & & & & & $\begin{array}{l}\text { compared to } \\
\text { SES-SFP• }\end{array}$ & $\begin{array}{l}\text { Standard vs. } \\
\text { modified versions }\end{array}$ \\
\hline SES: 1982 standard & 11 & 21.4 & $7.2-36.8$ & 2,980 & $p=.20$ & $p<.0001$ \\
\hline SES: 1982 with modification & 19 & 32.6 & $5.2-92.0$ & 4,798 & $\mathrm{n} / \mathrm{a}$ & \\
\hline SES: 1987 standard & 5 & 20.2 & $14.9-27.9$ & 2,032 & $p=.76$ & $p<.0001$ \\
\hline SES: 1987 with modification & 15 & 26.1 & $11.4-58.1$ & 3,801 & $\mathrm{n} / \mathrm{a}$ & \\
\hline SES-SFP standard & 5 & 19.8 & $1.1-29.9$ & 1,621 & $\begin{array}{l}\text { Comparison } \\
\text { measure }\end{array}$ & $p=.0007$ \\
\hline SES-SFP with modification & 3 & 25.6 & $14.5-37.2$ & 910 & $\mathrm{n} / \mathrm{a}$ & \\
\hline Abbey 2005 SES standard & 3 & 29.0 & $18.9-36.0$ & 585 & $p<.0001$ & \\
\hline Post-Refusal Persistence Scale $†$ & 3 & 36.9 & $18.3-49.3$ & 821 & $p<.0001$ & \\
\hline Revised Conflict Tactics Scaleł & 2 & 38.6 & $31.5-45.6$ & 1,122 & $p<.0001$ & \\
\hline Tyler 6 items standard & 2 & 46.4 & $43.3-49.0$ & 1,086 & $\sim p<.0001$ & \\
\hline Tyler 6 items with modification & 1 & $\mathrm{n} / \mathrm{a}$ & 47.0 & 308 & $\mathrm{n} / \mathrm{a}$ & \\
\hline CSS standard & 1 & $\mathrm{n} / \mathrm{a}$ & 49.0 & 39 & & \\
\hline CSS with modification & 1 & $\mathrm{n} / \mathrm{a}$ & 50.2 & 304 & & \\
\hline $\begin{array}{l}\text { Investigator Created/One } \\
\text { Citation }\end{array}$ & 8 & 22.2 & $6.3-67.7$ & 5,117 & & \\
\hline
\end{tabular}

Note. SES = Sexual Experiences Survey, SFP = short form perpetration. CSS = Coercive Sexuality Scale. Statistical comparison to the right of the bar.

- comparison of the standard version of that questionnaire to the standard version of the SES-SFP †all three versions of this questionnaire appeared to be somewhat different and were averaged $¥$ only data from the sexual coercion subscale used

the findings from the three questionnaires (standard and with modification) were averaged for comparison to the SES-SFP 
Table 3

Prevalence of Verbal Coercion and Rape by Measure Used

\begin{tabular}{|c|c|c|c|c|c|c|}
\hline \multirow[b]{2}{*}{ Measure } & \multirow[b]{2}{*}{$n$} & \multirow[b]{2}{*}{ Mean \% } & \multirow[b]{2}{*}{ Range \% } & \multirow[b]{2}{*}{ Summed n's } & \multicolumn{2}{|c|}{$\begin{array}{l}\text { Statistical Comparisons } \\
\end{array}$} \\
\hline & & & & & $\begin{array}{c}\text { compared to SES- } \\
\text { SFP• }\end{array}$ & $\begin{array}{c}\text { Standard vs. } \\
\text { modified versions }\end{array}$ \\
\hline \multicolumn{7}{|c|}{ Verbal Coercion } \\
\hline SES: 1982 standard & 11 & 16.0 & $5.2-25.1$ & 2,980 & $p<.0001$ & $p<.0001$ \\
\hline SES: 1982 with modification & 19 & 21.8 & $5.2-47.6$ & 4,798 & & \\
\hline SES: 1987 standard & 5 & 14.5 & $5.4-27.9$ & 2,032 & $p<.0001$ & $p=.003$ \\
\hline SES: 1987 with modification & 15 & 17.5 & $7.4-38.9$ & 3,801 & & \\
\hline SES-SFP standard & 5 & 10.2 & $4.5-17.5$ & 1,621 & comparison measure & $p<.0001$ \\
\hline SES-SFP with modification & 3 & 22.7 & $8.2-37.2$ & 910 & $\mathrm{n} / \mathrm{a}$ & \\
\hline Abbey 2005 SES standard & 3 & 17.1 & $11.4-21.2$ & 585 & $p<.0001$ & \\
\hline Tyler 6 items standard & 2 & 12.0 & $9.3-14.6$ & 1,086 & $\sim p<.0001$ & \\
\hline $\begin{array}{l}\text { Tyler } 6 \text { items with } \\
\text { modification }\end{array}$ & 1 & $\mathrm{n} / \mathrm{a}$ & 36.3 & 308 & & \\
\hline \multicolumn{7}{|c|}{ Rape } \\
\hline SES: 1982 standard & 11 & 4.8 & $1.6-8.2$ & 2,980 & $p=.0008$ & $p=.5$ \\
\hline SES: 1982 with modification & 19 & 4.5 & $0-15.5$ & 4,798 & & \\
\hline SES: 1987 standard & 5 & 5.0 & $4.8-5.2$ & 2,032 & $p=.005$ & $p=.5$ \\
\hline SES: 1987 with modification & 15 & 4.6 & $0-13.3$ & 3,801 & & \\
\hline SES-SFP standard & 5 & 7.2 & $1.1-12.9$ & 1,621 & comparison measure & $p=.007$ \\
\hline SES-SFP with modification & 3 & 4.5 & $0.5-8.5$ & 910 & $\mathrm{n} / \mathrm{a}$ & \\
\hline Abbey 2005 SES standard & 3 & 4.6 & $3.8-5.3$ & 585 & $p=.03$ & $\mathrm{n} / \mathrm{a}$ \\
\hline Tyler 6 items standard & 2 & 15.0 & $14.9-15.1$ & 1,086 & $\sim p<.0001$ & $\mathrm{n} / \mathrm{a}$ \\
\hline $\begin{array}{l}\text { Tyler } 6 \text { items with } \\
\text { modification }\end{array}$ & 1 & $\mathrm{n} / \mathrm{a}$ & 8.0 & 308 & & \\
\hline
\end{tabular}

Note. SES = Sexual Experiences Survey, SFP = short form perpetration.

- comparison of the standard version of that questionnaire to the standard version of the SES-SFP

$\sim$ the findings from the three questionnaires were averaged for comparison to the SES-SFP 
Table 4

Common Modifications and Effects on Prevalence Rates

\begin{tabular}{|c|c|c|c|c|}
\hline Modification & $\begin{array}{l}n \text { studies; } \\
\text { Summed n’s }\end{array}$ & $\begin{array}{l}\text { Any Sexual } \\
\text { Perpetration, } M \% \\
\end{array}$ & Verbal Coercion, $M \%$ & Rape, $M \%$ \\
\hline \multicolumn{5}{|c|}{ Changes to instructions } \\
\hline No & $51 ; 15,286$ & 27.6 & 19.9 & 6.4 \\
\hline \multirow[t]{2}{*}{ Yes } & $21 ; 5,214$ & 33.1 & 20.1 & 5.4 \\
\hline & & $* \mathrm{p}<.0001$ & Ns & $* p=.009$ \\
\hline \multicolumn{5}{|c|}{ Added alcohol/substance items } \\
\hline No & $56 ; 16,395$ & 27.1 & 20.4 & 6.6 \\
\hline \multirow[t]{2}{*}{ Yes } & $16 ; 4,105$ & 36.8 & 18.4 & 4.7 \\
\hline & & $* \mathrm{p}<.0001$ & $* p=.004$ & $* p<.0001$ \\
\hline \multicolumn{5}{|c|}{ Added verbal coercion items } \\
\hline No & $63 ; 17,928$ & 26.8 & 19.5 & 5.7 \\
\hline \multirow{2}{*}{ Yes } & $9 ; \quad 2,572$ & 46.2 & 24.5 & 10.2 \\
\hline & & $* \mathrm{p}<.0001$ & $* p<.0001$ & $* p<.0001$ \\
\hline \multicolumn{5}{|c|}{ Added sexual outcome items } \\
\hline No & $63 ; 18,535$ & 26.9 & 19.4 & 6.1 \\
\hline \multirow[t]{2}{*}{ Yes } & $9 ; \quad 1,965$ & 45.5 & 23.3 & 6.2 \\
\hline & & $* \mathrm{p}<.0001$ & $* p<.0001$ & ns \\
\hline
\end{tabular}

Note. ns $=$ not significant, $*$ indicates statistically significant difference for the no vs. yes comparison for that modification 
Table 5

Summary of Critical Findings

- Overall average prevalence rate for sexual perpetration broadly was $29.3 \%$, for verbal coercion was $19.0 \%$, and for rape was $6.5 \%$. These ranges varied wildly.

- There was a significant difference in average prevalence rates between studies that used a Sexual Experiences Survey (SES) based measure and those that did not. Non-SES-using studies found higher prevalence rates, on the order of a difference of 5.5 to 15.3 percentage points.

- We identified at least 16 different strategies for assessing sexual perpetration via questionnaire, not counting modifications made to standardized questionnaires.

- The SES or a variation thereof were by far the most common assessment strategy.

- The most recent version of the SES, the SES-Short Form Perpetration (SES-SFP) detected higher rates of rape than older versions of the SES but lower rates of verbal coercion and equivalent rates of overall sexual perpetration.

- Most of the time that a standardized questionnaire was used, it was modified or altered in some way (61.1\%).

- A total of nine common modifications were identified, the most frequent being changes to the instructions or response scale, adding alcohol or substance use items, adding verbal coercion items, and adding sexual outcome items.

Table 6

Key Recommendations for Practice, Policy, and Research

- $\quad$ Sexual perpetration in young men may be more common than thought. For individuals working with college men, routine screening for perpetration and related risk factors (alcohol use, sexual behavior, etc.) is recommended. It is highly likely that many young men consider the risky behavior of themselves and their peers as normative.

- Policy efforts that allocate greater resources (such as funding for basic, translational, and applied science) to understanding and preventing sexual perpetration are needed given the widespread nature of these behaviors.

- There is a great need for research on how to identify and prevent sexual perpetration in college men. However, we recommend such research be undertaken in the spirit of open science and transparency, more clearly documenting assessment strategies, descriptive data and findings, and better operationalization of key terms (e.g., sexual assault, sexual aggression, coercion, etc.)

- Measures that describe the tactic first, use a frequency scale response format, and randomize the order of items appear most promising for future research and use.

- The science of measurement of sexual perpetration has remained largely stagnant for the last 30 years; innovative interdisciplinary research is needed to establish boundary conditions, psychometric properties, and further explore this critical science. 


\section{Author biographies}

RaeAnn E. Anderson (Ph.D., University of Wisconsin-Milwaukee, 2015) is currently an Assistant Professor in Clinical Psychology at the University of North Dakota. She completed her postdoctoral training at Kent State University. Her research interests are understanding basic behavioral processes in sexual victimization and sexual perpetration in order to inform sexual assault risk reduction and prevention programs, respectively.

Kristin E. Silver is a Ph.D. student in Counseling Psychology at The University of Akron. Broadly speaking, her research and clinical interests are at the intersection of mental health and human rights. She is particularly passionate about: women's sexual health, pleasure, and empowerment; the causes and consequences of trauma, along with empirically supported treatments for marginalized populations (e.g., human trafficking survivors); and intersectional feminist therapy and interventions. Methodologically speaking, her interests include mixed methods, treatment outcome research, prevention programming, and quantitative scale construction.

Alyssa M. Ciampaglia (M.S., Saint Joseph’s University, 2017) has a master’s degree in experimental psychology. Her thesis, Testing Beck’s Specific Vulnerability Hypothesis with Male-Type Depression examined the potential for atypical gender-specific depression symptoms based on the way men are socialized to repress sadness and express anger. After defending her thesis and completing her degree, Alyssa began working as a clinical research coordinator at the Sleep Center at The Children's Hospital of Philadelphia. She presently coordinates for multiple $\mathrm{NIH}$ funded research projects. Her research interests are in promoting health and wellbeing of gender and sexual minorities and advocating for intersectionality as well as diversifying methodology in clinical psychology.

Amanda M. Vitale (BA, University of Michigan, 2015) is currently a research manager at Icahn School of Medicine. Her research interests are in traumatic brain injury and sleep, especially among veteran populations.

Douglas L. Delahanty (PhD, University of Pittsburgh) is a Professor of Psychology at Kent State University. He is a faculty member in experimental psychology and conducts research on the biological and psychological predictors of recovery from trauma in children and adults. 